\title{
PENDAMPINGAN PENYUSUNAN RESCHEDULE LIFESTYLE PASIEN HIPERTENSI
}

\author{
Windu Santoso ${ }^{1}$, Sri Sudarsih ${ }^{2}$ \\ 1,2 STIKES Bina Sehat BinaSehat PPNI Mojokerto \\ email: srisudarsih.ws@gmail.com
}

\begin{abstract}
ABSTRAK
Hipertensi merupakan penyebab kematian nomor satu di dunia setiap tahun. Tingginya angka kematian penderita hipertensi di Indonesia merupakan pertanda bahwa masyarakat masih belum memahami pentingnya kepatuhan dalam melakukan pengobatan dan perubahan gaya hidup (life style). Tujuan kegiatan pengabdian ini adalah sebagai upaya mempersiapkan ners fresh graduate yang merupakan tenaga kesehatan sehingga mampu mendampingi pasien hipertensi dalam merencanakan perubahan gaya hidup menjadi lebih sehat. Kegiatan pendampingan untuk ners fresh graduate dilaksanakan melalui Whatsaap dan google meet. Tahap persiapan berkoordinasi dengan 2 orang ners fresh graduate dan menentukan siapa yang akan menjadi peserta kegiatan. Tahapan pelaksanaan adalah menyusun skenario reschedule lifestyle card dan memberikan pendampingan dalam penyusunan reschedule lifestyle. Hari pertama hingga hari ketiga tim memberikan pendampingan, peserta mengidentifikasi gaya hidup penderita hipertensi dalam 1 minggu terakhir dan berdasarkan hasil identifikasi mengembangkan pola hidup yang lebih sehat. Melalui kegiatan pendampingan ini didapatkan hasil kemampuan ners fresh graduate dalam penyusunan reschedule lifestyle pasien hipertensi meningkat.
\end{abstract}

Kata Kunci : hipertensi; reschedule; lifestyle

\begin{abstract}
Hypertension is the number one cause of death in the world every year. The high mortality rate for hypertension sufferers in Indonesia is a sign that society still does not understand the essence of taking medication and changing lifestyle. The purpose of this service activity is to prepare new graduates who are health workers so that they can assist hypertensive patients in planning lifestyle changes to be healthier. Mentoring activities for new graduates are carried out through Whatsaap and google meet. The preparation stage coordinates with 2 new graduates and determines who will be participants in the activity. The stages of implementation are compiling a lifestyle card rescheduling scenario and assisting in preparing a lifestyle to reschedule. From the first day to the third day the team assisted, participants who lived the lifestyle of hypertensive sufferers within 1 week and based on the results of the examination developed a healthier lifestyle. Through this mentoring activity, the results of the ability of fresh graduate nurses in preparing hypertension patient lifestyle rescheduling have increased
\end{abstract}

Keywords: hypertension; reschedule; lifestyle 


\section{PENDAHULUAN}

Hipertensi merupakan salah satu penyakit kardiovaskuler yang paling umum dan paling banyak di sandang masyarakat. Penyakit ini menjadi penyebab nomor satu kematian di dunia setiap tahunnya. Hipertensi disebut sebagai si pembunuh senyap karena gejalanya sering tanpa keluhan. Biasanya, penderita tidak mengetahui kalau dirinya mengidap hipertensi dan baru diketahui setelah terjadi komplikasi (Kemenkes RI, 2019a). Tingginya angka kematian kardiovaskuler pada usia yang semakin muda, yang terutama berkaitan dengan hipertensi di Indonesia merupakan salah satu tanda bahwa masyarakat Indonesia masih kurang memahami pentingnya kepatuhan (compliance) dalam menjalankan pengobatan dan perubahan gaya hidup (lifestyle) (Rokom, 2014).

Jumlah penderita hipertensi di dunia terus meningkat setiap tahunnya, diperkirakan pada 2025 akan ada 1,5 miliar orang yang terkena hipertensi. Setiap tahun diperkirakan juga ada 9,4 juta orang meninggal akibat hipertensi dan komplikasi (Kemenkes RI, 2018). Riskesdas 2018 menunjukkan prevalensi Penyakit hipertensi mengalami kenaikan jika dibandingkan dengan Riskesdas 2013, hipertensi naik dari 25,8\% menjadi 34,1\% (Kemenkes RI, 2018). Data Riskesdas 2018 pada penduduk usia 15 tahun keatas didapatkan data faktor risiko seperti proporsi masyarakat yang kurang makan sayur dan buah sebesar 95,5\%, proporsi kurang aktifitas fisik 35,5\%, proporsi merokok 29,3\%, proporsi obesitas sentral 31\% dan proporsi obesitas umum 21,8\% (Kemenkes RI, 2019).

Berdasarkan data ini kita dapat melihat bahwa gaya hidup sehat masyarakat masih kurang sehingga perlu adanya peningkatan kesadaran dari masyarakat untuk mengubah gaya hidup menjadi lebih sehat. Dalam rangka melakukan modifikasi perilaku gaya hidup lebih sehat diperlukan adanya bantuan dari tenaga kesehatan untuk mendampingi masyarakat merencanakan aktivitas yang terkait dengan gaya hidup sehat. Berdasarkan hasil penelitian yang dilakukan oleh tim pengabdian Santoso dan Sudarsih tahun 2020 tentang kemampuan Ners Fresh Graduate dalam menyusun gaya hidup sehat pada pasien hipertensi didapatkan data bahwa dari 30 responden didapatkan mean kemampuan 67,17 , hal ini menunjukkan bahwa kemampuan dalam menyusun reschedule lifestyle pasien hipertensi masih rendah. Minimnya kemampuan perawat (Ners Fresh Graduate) dalam menyusun reshedule lifestyle penderita hipertensi akan menjadi hambatan dalam melakukan pendampingan untuk penderita hipertensi dalam merencanakan gaya hidup sehat

Kementerian Kesehatan menghimbau agar semua pihak baik pemerintah, swasta maupun masyarakat agar dapat berpartisipasi dan mendukung upaya pencegahan dan pengendalian hipertensi, menerapkan hidup sehat yang dimulai dari keluarga, mengendalikan faktor risiko hipertensi dengan deteksi dini dan modifikasi gaya hidup (lifestyle) (Kemenkes RI, 2019).

Tujuan kegiatan pengabdian ini adalah sebagai upaya mempersiapkan ners fresh graduate yang merupakan tenaga kesehatan sehingga mampu mendampingi pasien hipertensi dalam merencanakan perubahan gaya hidup menjadi lebih sehat. 


\section{MASALAH}

Berdasarkan analisa situasi diatas dapat dirumuskan adanya permasalahan kemampuan ners fresh graduate STIKES Bina sehat PPNI dalam menyusun reschedule lifestyle pasien hipertensi masih rendah dan belum pernah mengikutikegiatan pendampingan penyusunan reschedule lifestyle pasien hipertensi.

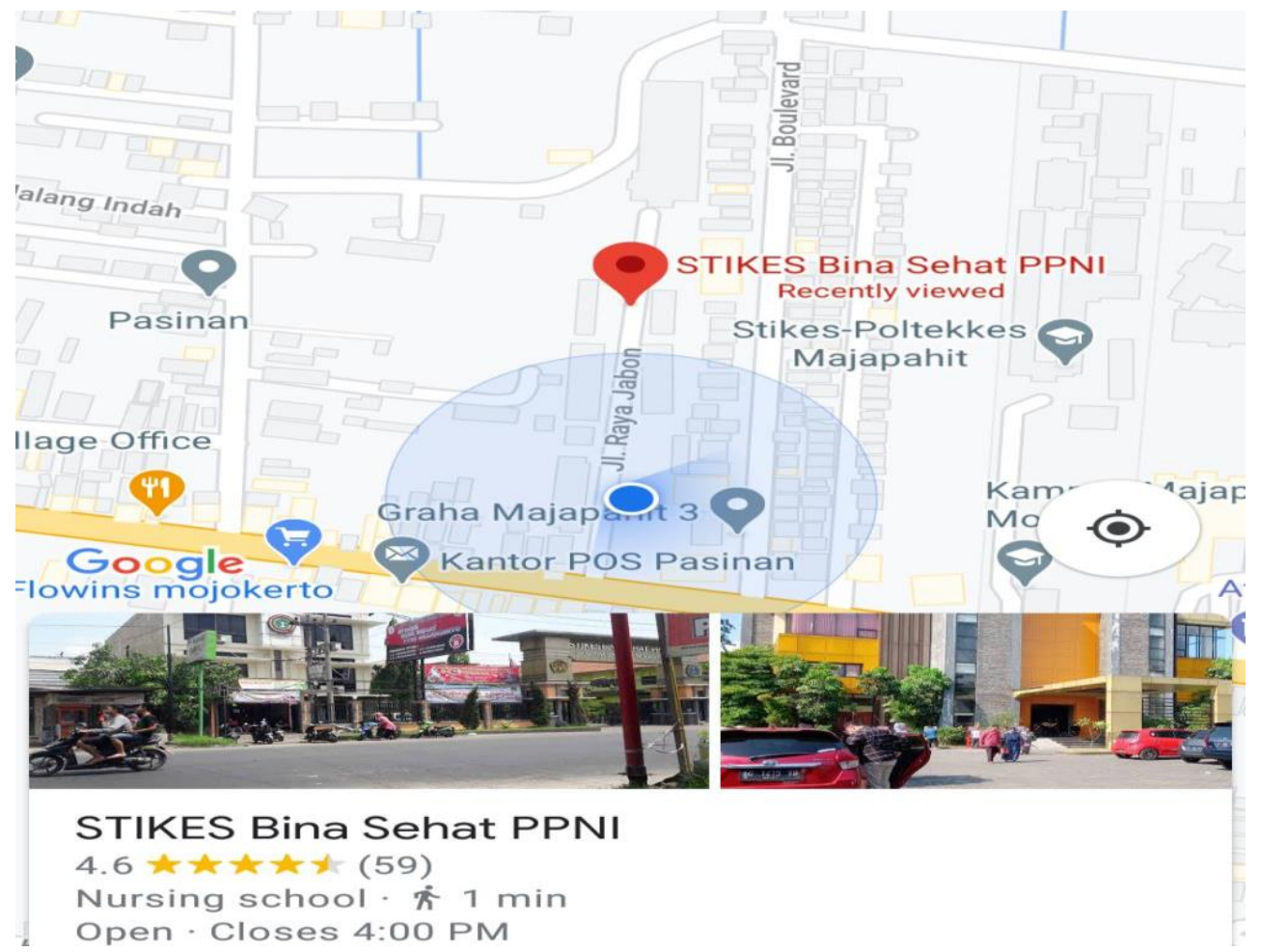

Gambar 2.1 Peta Lokasi Kegiatan Pengabdian Kepada Masyarakat

\section{METODE}

a. Tahap Persiapan

Tahap persiapan dari kegiatan pengabdian ini adalah tim pelaksana melakukan koordinasi dengan 2 orang ners fresh graduate STIKES Bina Sehat PPNI Mojokerto tentang pelaksanaan kegiatan pengabdian yang akan dilaksanakan agar mengetahui maksud dan tujuan kegiatan dan menentukan siapa saja yang akan menjadi peserta dalam kegiatan pendampingan penyusunan reschedule lifestyle.

b. Tahap Pelaksanaan

Tahapan pelaksanaan meliputi kegiatan menyusun Scenario Perubahan lifestyle card sebagai pedoman untuk mempermudah penyusunan reschedule lifestyle dan melakukan pendampingan penyusunan reschedule lifestyle.

c. Evaluasi

\section{i. Struktur}

Pelaksanakan kegiatan pendampingan yang dilakukan pada masa pandemi Covid-19 pada 30 orang peserta melalui media online yaitu menggunakan media Whatsaap dan google meet. 


\section{ii. Proses}

Kegiatan dilakanakan pada tanggal 26, 27 dan 29 Oktober 2020 sesuai dengan jadwal yang telah direncanakan. Pada hari pertama tim pelaksana pengabdian mengumpulkan seluruh peserta pengabdian melalui google meet dan menjelaskan tentang proses pelaksanaan kegiatan. Setelah itu tim pelaksana membagikan Reschedule lifestyle card kepada seluruh peserta pengabdian melalui Whatsaap untuk dilakukan pengisian. Dalam Reschedule lifestyle card sudah dilampirkan petunjuk pengisian dengan batas waktu pengisian 2 hari yaitu pada hari pertama dan hari kedua. Peserta diwajibkan untuk mencari 1 pasien hipertensi yang diambil dari anggota keluarga atau salah satu pasien di tempat kerja masing - masing . Jika ada hal yang kurang difahami pada saat pengisian, maka tim pelaksana pengabdian memberikan kesempatan pada peserta untuk berdiskusi dan beberapa peserta berdiskusi melalui Whatsaap grup dan ada beberapa yang berdiskusi melalui Whatsaap pribadi. Selanjutnya setelah peserta mengisi hasilnya dikirim kembali melalui Whatsapp. Tim pelaksana pengabdian mempelajari hasil pengisian Reschedule lifestyle card dari peserta dan memberikan feedback melalui Whatsaap kepada masing masing peserta.

\section{HASIL DAN PEMBAHASAN}

Hasil dari kegiatan pendampingan hari pertama didapatkan seluruh peserta masih harus merevisi pengisian Reschedule lifestyle card pada semua point gaya hidup sehat diantaranya melakukan aktivitas fisik (olah raga), asupan garam, mengurangi stress, mempertahankan berat badan ideal, merokok dan periksa tekanan darah. Hasil kegiatan pada hari ke dua didapatkan semua peserta masih harus merevisi beberapa poin saja dari gaya hidup sehat yaitu melakukan aktivitas fisik (olah raga), asupan garam, mengurangi stress, mempertahankan berat badan ideal dan periksa tekanan darah. Pada hari ke tiga tim pelaksana mengundang seluruh peserta untuk berdiskusi dan melakukan pendampingan melalui google meet. Pada hari ke tiga ini tim pelaksana menyampaikan kepada seluruh peserta tentang hal hal yang perlu ditekankan oleh peserta pada saat perilaku atau aktivitas aktivitas lama (old) pasien hipertensi karena hal itu akan menjadi dasar dalam merencanakan perilaku baru yang merupakan gaya hidup sehat yang akan diterapkan oleh pasien masing -masing dalam aktivitas sehari - hari. Hasil kegiatan pada hari ke tiga didapatkan seluruh peserta sudah lebih baik dalam menyusun reschedule lifestyle pasien hipertensi.

Kegiatan pendampingan reschedule lifestyle ini dikhususkan pada lifestyle pasien hipertensi, hal ini dikarenakan tim pengabdian melihat bahwa angka kejadian hipertensi dimasyarakat semakin meningkat. Hipertensi merupakan salah satu penyakit paling umum di seluruh dunia, mempengaruhi hampir 1,4 miliar orang di seluruh dunia dan merupakan faktor risiko yang signifikan untuk perkembangan penyakit kardiovaskular, penyakit ginjal, dan kematian (Joshi \& Ettinger, 2019). Gejala umum pada pasien hipertensi adalah sakit kepala, palpitasi, dan banyak keringat (WHO, 2017). Beberapa faktor resiko hipertensi adalah: usia lanjut, hubungan genetik (riwayat keluarga), obesitas atau kelebihan berat badan, asupan garam yang tinggi, penggunaan alkohol yang berbahaya, penggunaan tembakau, aktivitas fisik, kurangnya asupan kalium, diabetes dan 
dislipidemia. Kondisi khusus seperti diabetes, bahkan memiliki resiko hipertensi lebih tinggi (WHO, 2017). Hipertensi juga dipengaruhi oleh faktor genetik dan lingkungan termasuk pola makan, khususnya asupan natrium dan kalium. Studi telah mengungkapkan interaksi positif antara asupan natrium dan peningkatan tekanan darah (Ratios, Jeong, Jin, Kim, \& Shin, 2020).

Kegiatan pengabdian ini memilih upaya non farmakologi dalam pencegahan dan penataksanaan pasien hipertensi yang salah satunya adalah lifestyle. Tim pengabdian dalam kegiatan pendampingan rschedule lifestyle pada hari pertama meminta peserta pendampingan untuk mengidentifikasi gaya hidup pasien hipertesnsi atau mengidentifikasi perilaku lama pasien hipertensi selama 1 minggu kebelakang. Peserta didampingi sampai dengan hari ke tiga sehingga mampu menyusun reschedule lifestyle pasien hipertensi yang lebih baik. Berdasarkan hasil identifikasi perilaku lama ini maka peserta pendampingan reschedule lifestyle menyusun gaya hidup yang lebih sehat untuk pasien hipertensi dan dapat digunakan sebagai pedoman aktivitas sehari -hari yang meliputi melakukan aktifitas fisik, asupan garam, manajemen stress, berat badan (mempertahankan berat badan ideal), berhenti merokok, pemeriksaan tekanan darah.

Gaya hidup (lifestyle) dianjurkan untuk semua pasien dengan atau tanpa hipertensi dan apa pun terapi obatnya. Sebuah survei nasional terhadap pasien dewasa yang menghadiri praktik umum menunjukkan bahwa $62,7 \%$ kelebihan berat badan, 13,5\% adalah perokok setiap hari, 23\% meminum alkohol dengan tingkat risiko tinggi dan hanya $43 \%$ orang dewasa yang melakukan setidaknya 30 menit aktivitas fisik intensitas sedang setiap hari (Australia, 2016). Gaya hidup merupakan faktor risiko penting yang dapat dimodifikasi. Bukti nyata menunjukkan bahwa individu dengan gaya hidup yang sehat meliputi : tidak merokok, mengurangi risiko diabetes, aktivitas fisik teratur, dan diet sehat, menurunkan risiko stroke secara substansial (Rutten-Jacobs et al., 2018). Gaya hidup memainkan peran penting dalam pembangunan dan pemeliharaan hipertensi, dan pedoman dari beberapa organisasi merekomendasikan modifikasi gaya hidup sebagai intervensi lini pertama untuk hipertensi pasien (Joshi \& Ettinger, 2019).

Untuk mencegah hipertensi, perlu mengelola faktor-faktor risiko yang dapat dimodifikasi dengan mengadopsi gaya hidup sehat yang meliputi kontrol berat badan, meningkatkan aktivitas fisik, mengkonsumsi lebih sedikit garam, berhenti merokok, mengonsumsi lebih sedikit alkohol, dan mengelola stres emosional (WHO, 2017). Memodifikasi faktor gaya hidup dapat secara efektif menunda atau mencegah timbulnya hipertensi, berkontribusi pada penurunan tekanan darah pada pasien hipertensi yang dirawat dan, dalam beberapa kasus, dapat mengurangi atau meniadakan kebutuhan akan terapi antihipertensi (Australia, 2016). Menurut The American Heart Association's promosi tentang 7 gaya hidup sehat mencakup rekomendasi tentang diet, olahraga, dan pengendalian berat badan serta tekanan darah, gula darah, pengelolaan kolesterol, dan berhenti merokok. Perangkat sederhana, seperti aplikasi ponsel yang membantu individu memantau aktivitas mereka dapat membantu orang menyesuaikan gaya hidup mereka (Wardlaw \& Bath, 2019).

Gaya hidup sehat penderita hipertensi meliputi :

a. Monitor Tekanan darah

Pasien dengan hipertensi sering tidak disiplin dalam pengobatan atau pemeriksaan rutin karena mereka tidak memiliki gejala. Jika hipertensi diabaikan, dapat menyebabkan penyakit atau komplikasi yang 
lebih parah, seperti stroke, infark miokard dan penyakit ginjal kronis. Kontrol tekanan darah berkelanjutan dianjurkan untuk mencegah komplikasi ini, dengan kontrol teratur dapat menurunkan resiko stroke 30 \%, infark miocard $25 \%$ dan gagal ginjal kronis $23 \%$ (WHO, 2017). Pengelolaan pasien hipertensi dengan dua cara, pemeriksaan dan pengobatan secara teratur dan pengaturan pola hidup sehat. Ketika tekanaan darah relatif tinggi maka pemberian obat sangat di perlukan dan selanjutnya harus ditindaklanjuti dengan perubahan pola hidup sehat (life style).

b. Pengaturan Pola Makan

Pengaturan Pola Makan yang sehat dengan menambahkan sayuran dan buah, mengurangi konsumsi garam, makanan yang tinggi lemak dan selalu mengukur berat badan serta mempertahankan dalam rentang berat badan ideal perlu di biasakan. Penelitian yang dilakukan di korea yang meneliti hubungan diet natrium dan kalium dalam asupan makanan menunjukkan asupan natrium sangat perhubungan dengan resiko peningkatan resiko hipertensi, hal itu terjadi pada semua jenis kelamin. Menunjukkan hubungan yang sangat kuat perbandingan natrium dan kalium dalam diit (Ratios et al., 2020).

Pendekatan Diet untuk menghentikan Hipertensi (DASH), pola makan adalah pola makan sehat, awalnya disusun untuk diuji potensi penurunan tekanan darahnya efek. Diet DASH terdiri dari lebih banyak susu rendah lemak, daging tanpa lemak, buah dan sayuran, serta bijibijian, kacang-kacangan, dan lebih sedikit daging merah dan permen (Bathrellou et al., 2019). Diet Stop Hypertension (DASH) adalah a diet rendah lemak, tinggi buah-buahan dan sayuran, biji-bijian, unggas, ikan, dan kacang-kacangan, dengan sedikit daging merah, gula minuman manis atau makanan penutup (Marchand \& Jensen, 2018).Karena alasan ini, mengubah pola makan terbukti menjadi tugas yang sulit. Menimbang bahwa pilihan makanan merupakan proses kompleks yang dipengaruhi oleh beberapa faktor fisiologis, psikologis, sosial, dan lingkungan (Machín et al., 2018).

c. Pengaturan aktivitas olah raga

Olahraga yang sangat di rekomendasikan pada pasien hipertensi adalah aerobik misal jalan, berlari, berenang dan besepeda 150 menit per minggu atau 30 menit setiap hari selama 5-7 hari dalam satu minggu. Selain itu latihan fisik yang dapat memperkuat otot sangat direkomendasikan. Perencanaan aktivitas dengan pendekatan smart (Garrahy et al., 2020) yang terdiri dari spesifik, terukur, achievable, relevan dan berdasarkan waktu

d. Berhenti Merokok

Perilaku yang tidak sehat meliputi kebiasaan merokok, konsumsi alkohol dan sedikit makan sayur dan buah (Mcintosh, Krause, \& Ironson, 2020).

e. Manajemen stres

Stresor' adalah stimulus atau peristiwa yang dinilai atau dianggap tidak menyenangkan dan menyebabkan 'respons stres' yang terdiri dari serangkaian perubahan perilaku, emosional, dan biologis yang bertujuan untuk mempertahankan kesejahteraan organisme (Anisman, 2014). Stres adalah bagian utama dari kehidupan sehari-hari. Ini mencakup tekanan yang datang secara alami saat pasien kami menghadapi perubahan dan peristiwa hidup, seperti anak-anak meninggalkan rumah, sekolah baru, penyakit, menikah, berganti pekerjaan. Stres tidak selalu buruk bagi 
pasien kita. Stres dapat memfasilitasi pencapaian besar. Saat kita bekerja dengan pasien, penting untuk disadari bahwa tekanan dan ketegangan dapat memicu stres yang baik dan buruk (Snetselaar, 2007) .

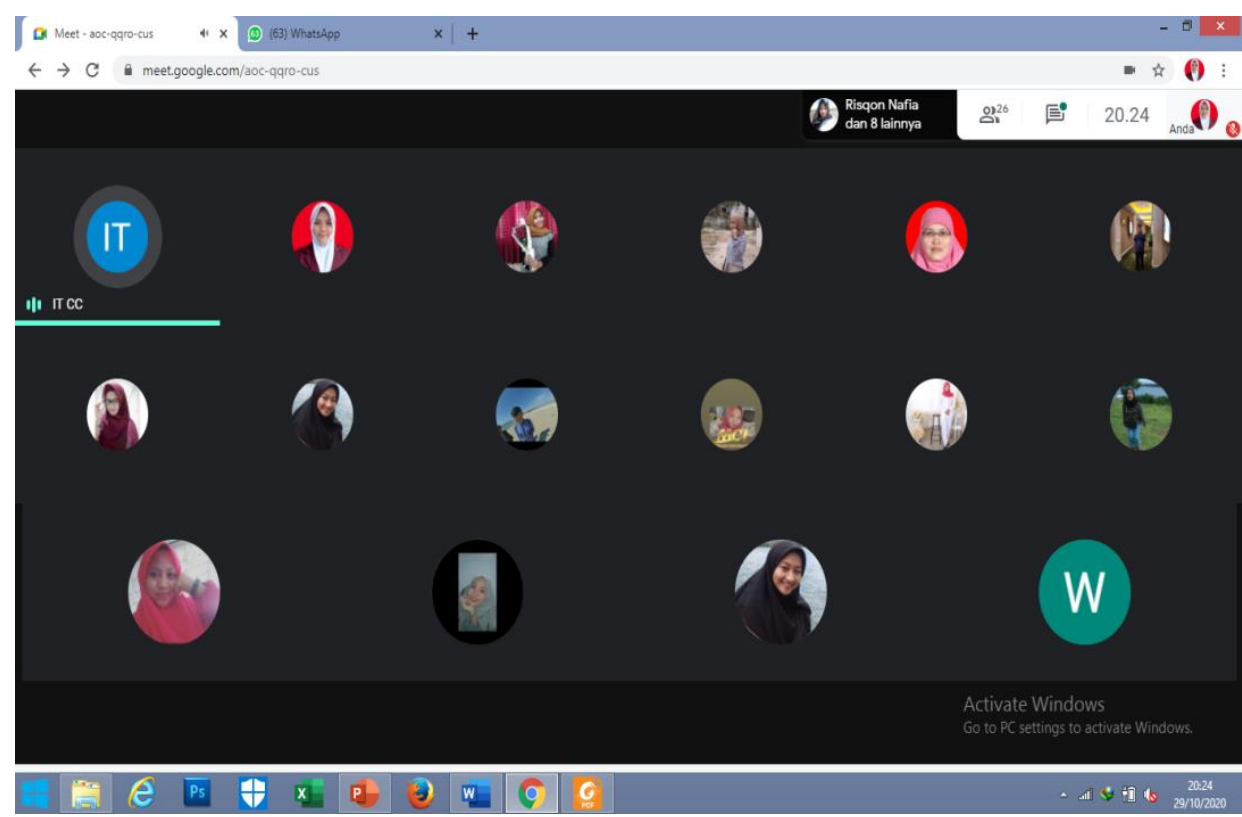

Gambar 1. Pendampingan reschedule lifestyle

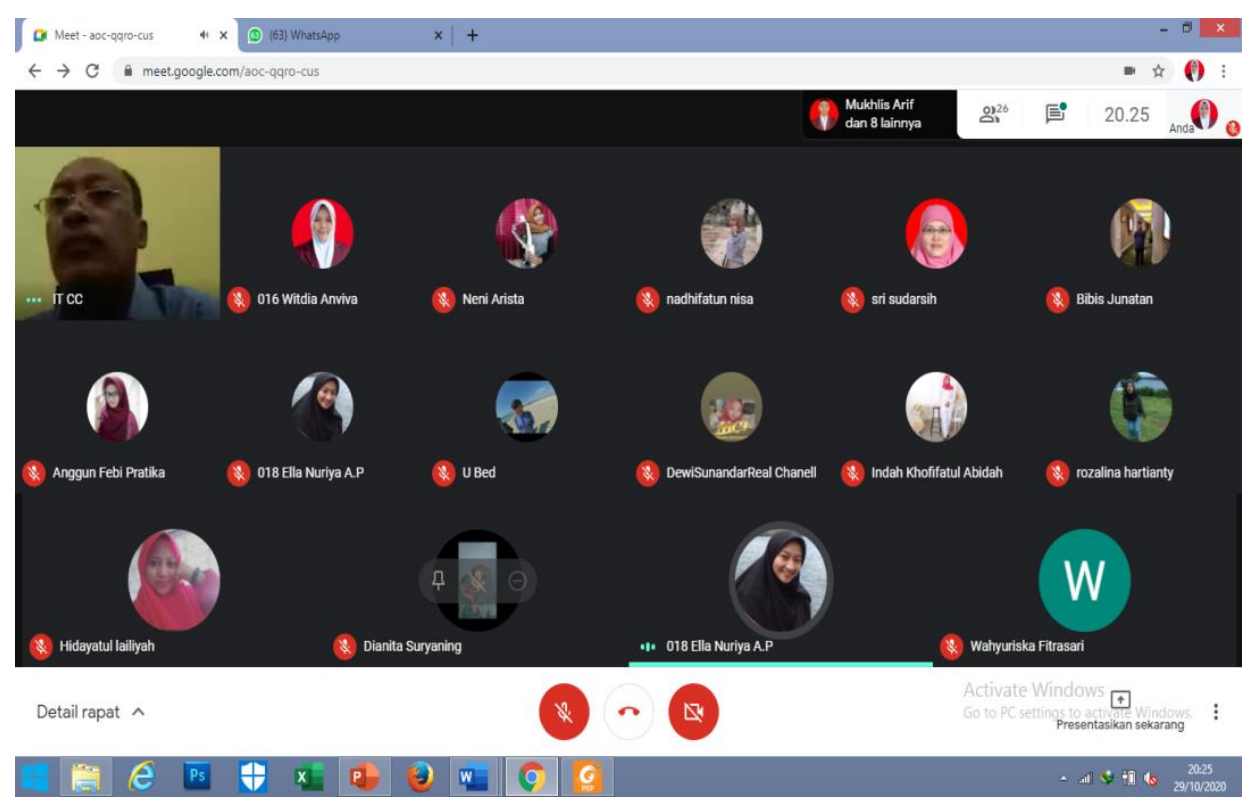

Gambar 2. Pendampingan reschedule lifestyle 


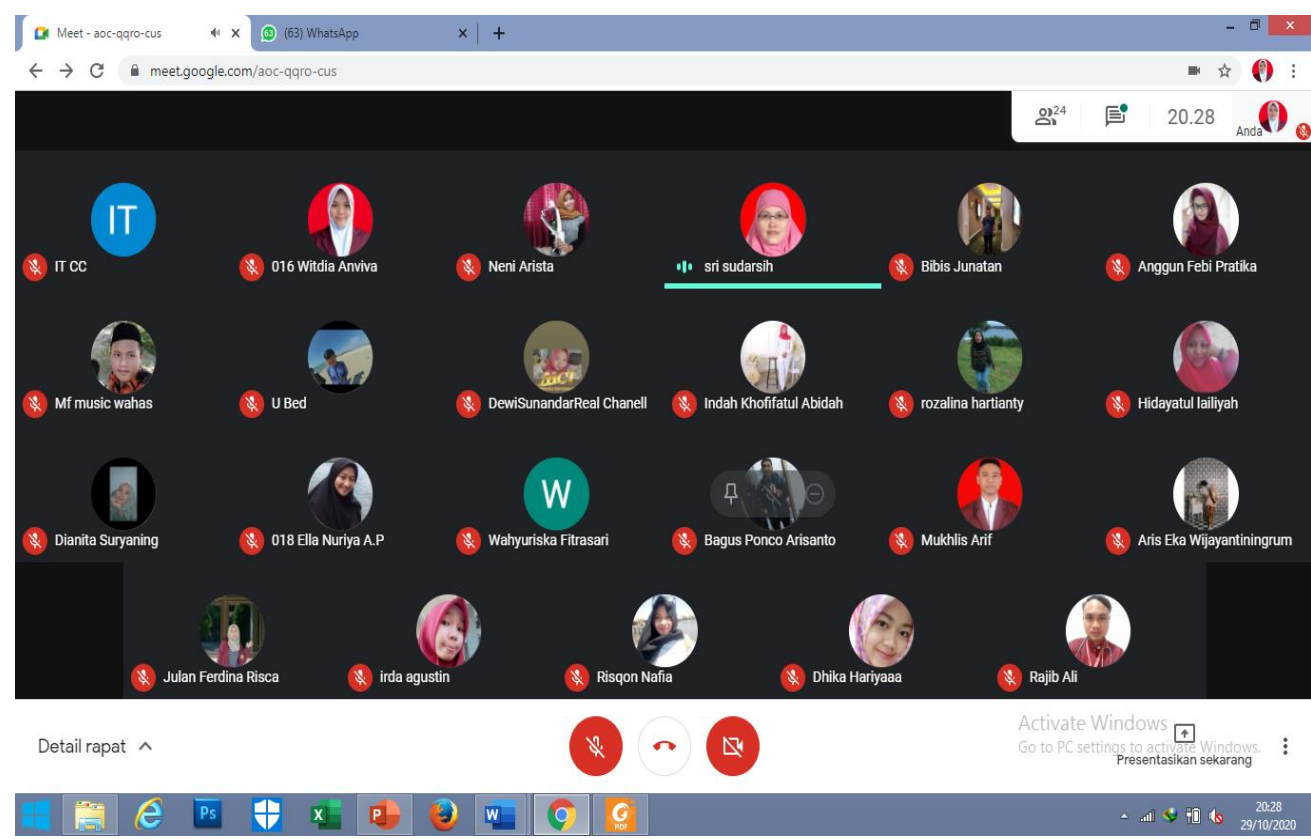

Gambar 3. Pendampingan reschedule lifestyle

\section{KESIMPULAN}

Kegiatan pendampingan penyusunan reschedule lifestyle ini berjalan dengan baik dan lancar serta sesuai dengan yang telah direncanakan. Seluruh peserta sangat antusias mengikuti kegiatan karena adalah bahwa kegiatan pengabdian ini memiliki target yang semuanya telah tercapai melalui luaran yang dihasilkan yaitu berupa reschedule lifestyle card meningkatnya kemampuan peserta kegiatan (ners fresh graduate) dalam menyusun reshedule lifestyle penderita hipertensi

\section{DAFTAR PUSTAKA}

Anisman, H. (2014). An Introduction to Stress \& Health Hormonal Changes Associated with Stressors. SAGE Publications, Inc. https://doi.org/http://dx.doi.org/10.4135/9781473920781.n3

Australia, N. H. F. of. (2016). Guideline for the diagnosis and management of hypertension in adults. Melbourne.

Bathrellou, E., Kontogianni, M. D., Chrysanthopoulou, E., Georgousopoulou, E., Chrysohoou, C., \& Pitsavos, C. (2019). Adherence to a DASH-style diet and cardiovascular disease risk: The 10-year follow-up of the ATTICA study. https://doi.org/10.1177/0260106019862995

Garrahy, E., Davison, K., Hardcastle, S., Brien, J. O., Pedersen, S., \& Williams, A. (2020). Exercise as cardiovascular medicine, 49(8), 483-488.

Joshi, S., \& Ettinger, L. (2019). Plant-Based Diets and Hypertension, 14(4), 397405. https://doi.org/10.1177/1559827619875411

Kemenkes RI. (2018). Hipertensi membunuh diam-diam, ketahui tekanan darah anda, 2-3.

Kemenkes RI. (2019). Hipertensi penyakit paling banyak diidap masyarakat. Retrieved from http://www.depkes.go.id/article/view/19051700002 
Machín, L., Aschemann-witzel, J., Patiño, A., Moratorio, X., Bandeira, E., Curutchet, M. R., ... Ares, G. (2018). Barriers and Facilitators to Implementing the Uruguayan Dietary Guidelines in Everyday Life : A Citizen Perspective. https://doi.org/10.1177/1090198117744243

Marchand, N. E., \& Jensen, M. K. (2018). The Role of Dietary and Lifestyle Factors in Maintaining Cognitive. https://doi.org/10.1177/1559827617701066

Mcintosh, R. C., Krause, N., \& Ironson, G. (2020). Do religious and spiritual identity confer risk for hypertension via psychosocial and lifestyle factors? https://doi.org/10.1177/1359105317748733

Ratios, S. P., Jeong, H., Jin, H., Kim, S., \& Shin, D. (2020). rs16998073 Variants and Their Associated Risk for.

Rokom. (2014). Kendalikan hipertensi. Retrieved from http://sehatnegeriku.kemkes.go.id/baca/rilis-

media/20140108/199549/kendalikan-hipertensi-galakkan-progra/

Rutten-Jacobs, L. C. A., Larsson, S. C., Malik, R., Rannikmäe, K., Sudlow, C. L., Dichgans, M., ... Traylor, M. (2018). Genetic risk, incident stroke, and the benefits of adhering to a healthy lifestyle: Cohort study of 306473 UK Biobank participants. BMJ (Online), 363. https://doi.org/10.1136/bmj.k4168

Snetselaar, L. (2007). Nutrition counseling for lifestyle change. the United States of America on. Retrieved from http://www.taylorandfrancis.com

Wardlaw, J. M., \& Bath, P. M. (2019). Stroke research in 2018: extended time windows, refined benefit, and lifestyle prevention targets. The Lancet Neurology, 18(1), 2-3. https://doi.org/10.1016/S1474-4422(18)30457-5

WHO. (2017). Diagnosis and management for patients with hypertension. Management. 